\title{
CONSUMERS' PERCEPTION OF RISK TOWARDS ARTIFICIAL INTELIIGENGE TECHNOLOGIES USED IN TRADE: A SCALE DEVELOPMENT STUDY
}

\author{
Pinar Aytekin ${ }^{1}$, Florina Oana Virlanuta ${ }^{2 *}$, Huseyin Guven ${ }^{3}$, Silvius Stanciu ${ }^{4}$ \\ and Ipek Bolakca ${ }^{5}$ \\ ${ }^{1), 5)}$ Izmir Democracy University, Turkey. \\ ${ }^{2), 4)}$ Dunărea de Jos University of Galati, Romania. \\ ${ }^{3)}$ Karabaglar Guidance and Research Center, Turkey.
}

Please cite this article as:

Aytekin, P., Virlanuta, F.O., Guven, H., Stanciu, S. and Bolakca, I., 2021. Consumers' Perception of Risk Towards Artificial Intelligence Technologies Used in Trade: A Scale Development Study. Amfiteatru Economic, 23(56), pp. 65-86.
Article History

Received: 25 September 2020

Revised: 8 November 2020

Accepted: 21 December 2020

\begin{abstract}
In today's digitalizing world, internet, mobile technologies, nanotechnologies and learning algorithms continue to develop and gain essential places in our lives. The use of artificial intelligence in wholesale and retail trade enable better analysis of customer requests and the development of effective marketing strategies. However, although these cutting-edge technologies provide significant advantages to businesses, some risks may arise as these technologies continuously develop, and it eventually becomes harder to control the pace of development. Many famous scientists and entrepreneurs are worried that artificial intelligence could have negative consequences for humanity if it does not develop safely, and they suggest that urgent measures need to be taken as they believe that it may pose a significant threat to humanity. The starting point of this study is to learn the point of view of consumers on this technology, as well as scientists or entrepreneurs.

The purpose of this study is to determine how consumers perceive these risks. In this direction, the literature focused on the issues related to artificial intelligence technologies in trade was examined. In light of the information obtained from the literature, the Artificial Intelligence Technologies Used in Trade Risk Perception Scale (AITUTRPS) was developed.
\end{abstract}

Keywords: artificial intelligence, trade technique, risk perception, scale development

JEL Classification: D81, L81, M21

* Corresponding author, Florina Oana Virlanuta - e-mail: florina.virlanuta@ugal.ro 


\section{Introduction}

Technologies such as artificial intelligence, robotics and mechatronic developments, big data, Internet of Things, augmented reality, data mining, hologram and wearable electronics (Dirican, 2015), which have been used in business life in recent years, have made it necessary for companies to restructure their sales strategies. Applying artificial intelligence technologies to sales strategies enables businesses to know their customers very well. In this direction, it is possible to provide a personalized experience by sending messages, content, and even small surprises specific to each customer. Businesses can also optimize their sales campaigns by using artificial intelligence technologies in their marketing activities. For example, it can be determined which loyal customers have not made purchases from the company recently, and even unique campaigns can be offered to these customers, and they can be regained (Kietmann, Paschien and Trieen, 2018).

With artificial intelligence technology, making transactions faster and accessing large databases has reached a level that people cannot entirely control. For this reason, many scientists and entrepreneurs recommend taking urgent measures regarding artificial intelligence technology in order not to create a significant threat to humanity (Brockman, 2015). Also, some famous scientists have concerns that this technology may have consequences for humanity if it does not develop safely (Bostrom, 2014; BBC, 2015; Russell, 2015; The Guardian, 2015). The possibility that artificial intelligence technologies may harm humanity as they develop is a matter of concern.

The purpose of this study is to develop a scale to measure how consumers perceive risks related to artificial intelligence technologies used in trade. The lack of a specific scale to measure the risk perceptions of consumers towards artificial intelligence technologies used in trade makes this study necessary and essential in the literature. First, in the study, the artificial intelligence technologies used in trade and the risks encountered were mentioned. In the methodology, the stages of the scale development study were discussed. Finally, the findings obtained from the analyses were included, and recommendations were made within the scope of the findings and results.

\section{Literature review}

\subsection{Artificial Intelligence Technology and Its Application in Trade}

Artificial intelligence is a system that can make logical calculations, solve a problem on its own and reprogram (Sterne, 2017). Artificial intelligence technology has reached the human level in a shorter time than it was expected in some areas, and it has already developed in a way beyond human control. In 1997, the world-famous chess champion Garry Kasparov was defeated in a chess game by a computer called Deep Blue (Silver, 2012). Watson, an artificial intelligence program developed by IBM in 2011, defeated two players in the word game Jeopardy (PC World, 2011). In 2015, the software named Cepheus had theoretically analysed the poker game "Heads-up Limit Texas Hold'em" and learned to bluff upon playing million times (Bowling, et al., 2015). In this direction, it is understood that artificial intelligence is a technology that learns very quickly, develops, and progresses rapidly.

European Research Project READ has developed Transcribus software specifically for digitizing old books. This software uploads the captured photos to the platform server and then digitizes them by reading the manuscripts (Euronews, 2018). Investments in artificial 
intelligence technologies, which progressively develop to the present, continue to increase. This investment, which was 9.5 billion dollars in 2018 , is predicted to be 118.6 billion dollars by 2025 (Statista, 2020).

Collecting a large amount of customer data, predicting the next step of the customer, and using concepts such as machine learning to improve customer relations are among the use of artificial intelligence technologies in wholesale and retail trade (Tjepkema, 2019). In today's business world, marketers must get to know their target audience well and predict their possible behaviours in the increasing information stack.

Providing personalized content about brands using artificial intelligence technology is a typical example of the use of artificial intelligence in trade. For example, thanks to an application run by IBM Watson and the famous sportswear company Under Armor, information and data such as the route the athlete, the duration of sports activity, the diet, and the weather are evaluated, and recommendations for exercise and nutrition are made. In London, M\&C Saatchi positioned a camera with artificial intelligence technology on a digital poster, and with the help of the camera, the facial movements of the people looking at the poster were analysed and depending on the level of interest in the poster, the strategy was modified, and the advertisements reached the target exactly (Ulutaş Ertuğrul, 2019).

In wholesale and retail trade, augmented reality applications are among the artificial intelligence technologies that have been used in recent years. Augmented reality is about combining the real and virtual world in real-time in a 3D environment. For example, the Marshall augmented reality application allows the customer to make colour tests and determine the most suitable colour for their home before painting the walls (Ayvaz, 2014). This allows the customer to experience different paint colours, albeit virtually, and to make a more comfortable decision.

Hologram technology is the virtual presentation of an object in 3D. For example, a customer who wants to buy a sneaker can think as if he/she is holding the shoe thanks to hologram technology on the Internet, which helps him make decisions easier (Kulabaş, 2017). Thiraviyam (2018) also mentioned that while watching the make-up video of a famous person on YouTube, cosmetic products appear before the consumer and machine vision and natural language processing technology are used to make these products attractive to the customer.

Levi's has created a virtual assistant that works with artificial intelligence to help users who want to shop from websites via Facebook Messenger. While browsing the website, users can get fashion suggestions, communicate from their mobile phones or laptops, and experience personalized shopping from wherever they want (Levi Strauss \& Co, 2017). Therefore, the personalized experience offered through the virtual assistant will enable the customer to visit the website and shop more.

West Elm, which offers home decoration products, tries to offer personalized recommendations with the help of Pinterest Style Finder by making use of the customer data on Pinterest, which is the world's most extensive idea-collection on the Internet; that is, the company first recognizes the previous posts of customers and modifies its recommendation according to their colour and style preferences (O'Shea, 2017).

The American Mail Company UPS allocates \$1 billion a year for technology investments and makes use of artificial intelligence technologies to save over \$200 million annually in all its 
global operations. By using an artificial intelligence chatbots to improve customer experience, UPS can respond wholly and quickly to customers' questions about tracking their shipments. These chatbots can even learn pricing information and connect to chat with customers through many social communication channels. UPS also uses ORION (On-Road Integrated Optimization and Navigation), a highly sophisticated artificial intelligence platform developed by the company that is at the centre of the company's operations. This platform plans and optimizes the routes of loads received by UPS drivers with algorithms. Thus, as soon as packages are received, fast, timely and efficient routes are created (Şentürk, 2018). In terms of time and effort spent, this application is very advantageous for a mail company.

The artificial intelligence-based smart personal shopping assistant ShopBot in eBay's Facebook Messenger application can recommend the most suitable products from the list of one billion products. This assistant, with which customers can easily communicate, asks them questions to better understand their requests and needs and directs them to suitable products accordingly (Pittman, 2016). Thus, the customer can easily find an affordable and wished product without wasting much time.

Generally, it is difficult for a business to provide a personalized experience to its customers if the number of customers is high. However, it becomes easier to offer this experience with artificial intelligence technology. However, many scientists have warned that continuously developing artificial intelligence technologies may have adverse effects. The CEO of Tesla Motors, entrepreneur and investor Elon Musk stated that the security of artificial intelligence technology is fundamental and he donated $\$ 10$ million to an artificial intelligence research institute that aims to make artificial intelligence beneficial to humanity (The Guardian, 2015).

Stephen Hawking stated that artificial intelligence is very advanced and useful. However, he said he was worried that it could reach a level that could surpass human intelligence. According to Stephen Hawking, "Artificial intelligence can continue to improve itself and even reformat itself. Human beings, limited to a prolonged biological evolution, cannot compete with this kind of power" (Jones, 2014). In the 100-page report published by international security experts on the probable dangers of artificial intelligence, they warned the developers of artificial intelligence to make more efforts to prevent the abuse of technology (BBC, 2018). This report shows that artificial intelligence is beginning to be recognized as dangerous if not used correctly and reliably in the future.

\subsection{Possible Risks Related to Artificial Intelligence Technologies Used in Wholesale and Retail Trade}

Artificial intelligence technology, as mentioned above, is a technology that provides benefits in many areas, but it can cause dangerous consequences. Shahar Avin, from the Centre for Existential Risk Research at the University of Cambridge, spoke of scenarios that artificial intelligence could be used maliciously soon. According to these scenarios, “AlphaGo game, developed by Google's artificial intelligence company DeepMind, may be used by hackers to find new ways to exploit new patterns and codes, a malicious person may purchase a drone and target a specific person by training it with face recognition software; also, bots can be automated, fake videos may be used for political manipulation, or hackers may even use voice synthesis to impersonate targets" (Wakefield, 2018). 
Artificial intelligence technology is also used in many marketing-related areas such as lowering advertising costs, providing better content to customers, audience targeting and market segmentation. $88 \%$ of marketers believe that investing in artificial intelligence technology will have a positive effect (Econsultancy, 2018), but although artificial intelligence technology contributes positively to the wholesale and retail trade field, it can also have negative consequences when not used correctly and carefully.

Marketers realize that in every field they choose to use artificial intelligence technologies, marketing strategies are reshaped, and the business is significantly affected. On the other hand, the threats that this technology may bring along should not be ignored. In 2016, a driverless vehicle developed by Nvidia set off in Monmouth, New Jersey, and this vehicle did not even follow a single instruction provided by the engineer or programmer. The car learned to drive by itself, watching how the people in the other vehicles were driving. Possibilities such as the driverless vehicle hitting the tree in the future or suddenly stopping at the green light worry the experts (Knight, 2017). This example shows that some security issues may arise. Another security issue occurred in Amazon's warehouse in the state of New Jersey. Twenty-four employees were hospitalized as an artificial intelligence robot accidentally broke the bear removal spray in the warehouse (CNNTURK, 2018). It is worrying to see that gradually improving artificial intelligence causes such an accident and harms the employees. Therefore, it is critical to control such robots very well and prepare the necessary environment for safe and decent operation. Otherwise, unexpected results may occur.

There are growing concerns about artificial intelligence (AI) violating personal privacy. The world-famous Nike company receives customized shoe orders. However, while the customer chooses the shoe, the brand can collect various data in the background and develop various strategies by using estimated models (Antonio, 2017). In this sense, using customer data without informing the customer for future sale strategies is an ethical question.

In the digital world, persuasion architecture can be built to reach billions thanks to artificial intelligence technology (big data and machine learning). Ads can target individuals one by one, penetrate them on a personal level by detecting their weak points, and these ads can even be sent to everyone's phone screen. Especially, companies such as Facebook, Google, and Amazon use algorithms to click on ads (Tüfekçi, 2018). There are concerns that computers have begun to take over business skills, including the quality of thinking, as they become more and more established in our lives (Dedeoğlu, 2006).

Although artificial intelligence is an essential innovation in trade applications, they cause more and more people to lose their jobs. According to the May 2017 report of Cornstone Capital Group, approximately 6 million job losses are foreseen in the retail sector (Shavel, Vanderzeil and Currier, 2017). In the retail industry, especially salespeople, cashiers, transport workers, and order clerks have roles open to automation. E-commerce giant Amazon has developed the Amazon Go name as a cashier-free store form. In this format, the content of shopping carts is automatically detected, and sensors perform the billing process when customers leave the store (Morris, 2017). At Cafe X in San Francisco, coffee is prepared by a robot. This robot prepares the coffee within a minute as specified when ordered, receives the payment, and waits for the customer to come and receive the coffee within six minutes (Yamak, 2017). If such examples increase, job loss will be inevitable for baristas as well. The job loss problem also applies to the management level. In a study conducted by Young and Cormier (2014), the idea of whether robots should be managers or 
not was investigated. After all, although a human manager is likely to be perceived as an authority, about $46 \%$ of the participants obeyed the robots.

Using a system based on artificial intelligence has some drawbacks because artificial intelligence has quite a few shortcomings in terms of morality and ethical values (Parry, Cohen and Bhattacharya, 2016). The relationship of artificial intelligence with ethical values has become heavily debated, especially in recent years. In particular, the problem of emotions not being entirely modelled causes paradoxes, such as how an artificial intelligence-based system should make decisions at the stage of ethical dilemmas (Köse, 2018a). Judgment quality, which enables to distinguish between good/bad, right/wrong, and the quality of decision making by combining reason and conscience, are critical in artificial intelligence. Whether artificial intelligence can bear responsibility for a problem, its accountability, obligations, and which powers can be assigned/delegated to artificial intelligence are considered essential issues (Dedeoğlu, 2006). It is a question of how artificial intelligence can make sense of ethical values that are cared for by people. It is a matter of curiosity to what extent a machine that learns on its own and whose behaviour cannot be directed will comply with ethical values in the future (Köse, 2018b). When a driverless vehicle's brakes fail, it is a matter of concern how it will make a sensible decision when it accelerates into a crowded crosswalk, faced with the difficult choice of mowing down a large group of older people or steering a woman pushing the stroller (The Associated Press, 2017).

As it is often challenging to document the processes performed by artificial intelligence systems, it may take a long time for such applications to gain trust (Henkoğlu, 2019). In an experiment conducted at the University of Bologna, the two opposing algorithms did not fight each other to find the lowest and most competitive price but instead misled users by offering high-priced products. The fact that the artificial intelligence algorithms did not leave any trace that they performed joint action was found to be alarming for the scientists who conducted the experiment. This shows that AI algorithms can learn to cooperate and oppose people without communicating or being told to do so. According to the popular science and technology magazine called Mechanics, such algorithms currently account for the vast majority of prices in online marketplaces such as Amazon (Altan, 2019). These experiences show that we may encounter ethical issues related to artificial intelligence.

\section{Research methodology}

While the use of artificial intelligence in wholesale and retail trade is gradually increasing, it also brings some problems. These problems can change the perspective on this technology. As mentioned above, some risks may arise regarding this technology. The purpose of this study is to determine how consumers perceive these risks. In this direction, it is aimed to develop the Artificial Intelligence Technologies Used in Trade Risk Perception Scale (AITUTRPS) to measure the risk perceptions of consumers towards artificial intelligence technologies used in trade. The absence of a scale on this subject in the literature makes the research valuable. Since this research is a perception scale development study, scanning method was used. Large-scale samples are not required as item analysis, and consistency of items with the whole scale will be examined instead of the validity and reliability of the scale in pilot applications. If the number of items on the scale in the pilot application is up to 30, then a sample size of around 50 will be sufficient (Seçer, 2015). Since the pilot application of the study was conducted on 51 people, it meets the 
sample size. If multivariate analyses are to be used in the research, the conditions required by these analyses should be considered as the sample size.

In cases where exploratory and confirmatory factor analysis will be used, a sample size of over 200 is considered sufficient in terms of reliability (Kline, 2005). Bryman and Cramer (2001) stated that the value obtained by multiplying the number of items in the scale by five or ten should be taken as a criterion in determining the number of participants. While Ho (2006) suggests that the sample size should not fall below 100, he mentions that this number should exceed five times the number of variables (items), from a more acceptable point of view, the number of items should be ten times. Since the main application was carried out on 205 people, sufficient sample size was met to perform factor analysis.

The data obtained as a result of the application of the scales were subjected to statistical evaluation with SPSS 22.0 and AMOS 20.0 statistical data analysis programs. The data collection tool used in the study consists of two parts: The Artificial Intelligence Technologies Used in Trade Risk Perception Scale (AITUTRPS) and the Demographic Information Form. The gender, age, profession, income, and education levels of the participants were asked in the Demographic Information Form. The applications during the design of AITUTRPS are as follows:

\section{a) Item Creation Stage}

At this stage, the sources in the literature such as: Dedeoğlu, 2006; Bostrom, 2014; Young and Cormier, 2014; Brockman, 2015; Russell, 2015; The Guardian, 2015; Parry, Cohen and Bhattacharya, 2016; Antonio, 2017; Knight, 2017; Morris, 2017; Shavel, Vanderzeil and Currier, 2017; The Associated Press, 2017; Yamak, 2017; BBC, 2018; CNNTURK, 2018; Köse, 2018a,b; Tüfekçi, 2018; Wakefield, 2018; Altan, 2019; Henkoğlu, 2019 were used to form the scale, and while preparing these items, attention was paid not to include more than one judgment/perception. Besides, positive items used in the scale were graded as I strongly agree and I agree, while negative items were graded as Strongly disagree and Disagree. The Undecided option was used for items that did not contain a positive or negative statement.

\section{b) Consultation to Expert Opinion Stage}

There are three types of validity: scope (content), compliance and structure. One or more of these validity types are suitable according to the characteristics of the measurement tool used in the study. At this stage, the adequacy of the scale in terms of scope (content) validity was examined. Content validity exactly means the degree to which items represent. This validity is provided when the items are first selected for the test (Field and Hole, 2019). In determining the scope validity of the scale, the opinions of economics and engineering faculty members and business administration professionals were consulted. Expert opinions were obtained through a form that provides three categories of evaluation: item needed, item useful but not sufficient and item unnecessary. Some modifications have been made by considering the opinions and criticisms made by experts. The scope validity of AITUTRPS was ensured by considering the collective opinions of the experts.

\section{c) Preliminary Trial Phase}

A draft scale consisting of a total of 20 items was created for the pre-trial and applied to 51 people in total in October 2019. In the study, the reliability (internal consistency) of the scale to determine the participants' risk perceptions about artificial intelligence 
technologies used in wholesale and retail trade was examined by item analysis, and in addition to item analysis based on the difference between lower-upper group averages, item analysis based on correlation was also performed. The Cronbach alpha reliability coefficient is widely used to determine the reliability of the scales used to measure psychological characteristics. The Cronbach Alpha Reliability Coefficient of the scale consisting of 20 items was determined as $(\alpha=0.899)$. The Cronbach Alpha reliability coefficient value is exceptionally reliable over 0.90 , highly reliable between 0.90 and 0.80 , and reliable between 0.79 and 0.70 (Cohen, Manion and Morrison, 2007). According to these values, the draft scale seems to be highly reliable. While item selection was made using the item analysis technique based on the difference between the sub-upper group averages (based on the internal consistency criterion) applied to 20 items in the trial form of the scale, the scale scores of the individuals were ranked in descending order. According to this ranking, 14 people constituting the first $27 \%$ of the group of 51 people were determined as the upper group, and the last 14 people constituting the last $27 \%$ as the sub group. For each scale item of the $27 \%$ lower-upper groups at both ends of the scale scores distribution, the difference between the t-test for independent groups and their averages was examined. The t-test results for the item averages of the Lower 27\% and Upper 27\% groups of the scale are shown in Table 1.

Table no. 1. T-Test Results for the Item Averages of the Lower 27\% and Upper $27 \%$ Groups of the Scale

\begin{tabular}{|c|c|c|c|c|c|c|c|}
\hline Item & & $\mathbf{N}$ & Mean & Std. d. & df & $\mathbf{t}$ & $\mathbf{p}$ \\
\hline \multirow{2}{*}{ Item 1} & Upper Group & 14 & 4.43 & 0.51 & \multirow{2}{*}{26} & \multirow{2}{*}{6.500} & \multirow{2}{*}{0.000} \\
\hline & Lower Group & 14 & 2.58 & 0.94 & & & \\
\hline \multirow{2}{*}{ Item 2} & Upper Group & 14 & 4.14 & 0.53 & \multirow{2}{*}{26} & \multirow{2}{*}{9.774} & \multirow{2}{*}{0.000} \\
\hline & Lower Group & 14 & 2.29 & 0.47 & & & \\
\hline \multirow{2}{*}{ Item 3} & Upper Group & 14 & 4.64 & 0.50 & \multirow{2}{*}{26} & \multirow{2}{*}{4.053} & \multirow{2}{*}{0.000} \\
\hline & Lower Group & 14 & 3.14 & 1.29 & & & \\
\hline \multirow{2}{*}{ Item 4} & Upper Group & 14 & 4.07 & 0.92 & \multirow{2}{*}{26} & \multirow{2}{*}{3.606} & \multirow{2}{*}{0.001} \\
\hline & Lower Group & 14 & 2.71 & 1.07 & & & \\
\hline \multirow{2}{*}{ Item 5} & Upper Group & 14 & 4.00 & 0.78 & \multirow{2}{*}{26} & \multirow{2}{*}{3.994} & \multirow{2}{*}{0.000} \\
\hline & Lower Group & 14 & 2.71 & 0.91 & & & \\
\hline \multirow{2}{*}{ Item 6} & Upper Group & 14 & 4.43 & 0.51 & \multirow{2}{*}{26} & \multirow{2}{*}{3.045} & \multirow[b]{2}{*}{0.005} \\
\hline & Lower Group & 14 & 3.50 & 1.02 & & & \\
\hline \multirow{2}{*}{ Item 7} & Upper Group & 14 & 3.43 & 1.02 & \multirow{2}{*}{26} & \multirow{2}{*}{1.427} & \multirow{2}{*}{0.166} \\
\hline & Lower Group & 14 & 2.93 & 0.83 & & & \\
\hline \multirow{2}{*}{ Item 8} & Upper Group & 14 & 3.14 & 0.86 & \multirow{2}{*}{26} & \multirow{2}{*}{2.550} & \multirow{2}{*}{0.017} \\
\hline & Lower Group & 14 & 2.26 & 0.91 & & & \\
\hline \multirow{2}{*}{ Item 9} & Upper Group & 14 & 4.29 & 0.47 & \multirow{2}{*}{26} & \multirow{2}{*}{6.379} & (2000 \\
\hline & Lower Group & 14 & 2.64 & 0.84 & & & 0.000 \\
\hline & Upper Group & 14 & 4.21 & 0.80 & $0 x$ & רחת & 000 \\
\hline Item 10 & Lower Group & 14 & 3.00 & 0.88 & 26 & 3.823 & 0.001 \\
\hline
\end{tabular}




\begin{tabular}{|c|c|c|c|c|c|c|c|}
\hline Item & & $\mathbf{N}$ & Mean & Std. d. & df & $\mathbf{t}$ & $\mathbf{p}$ \\
\hline \multirow{2}{*}{ Item 11} & Upper Group & 14 & 4.21 & 0.58 & \multirow{2}{*}{26} & \multirow{2}{*}{4.172} & \multirow{2}{*}{0.000} \\
\hline & Lower Group & 14 & 2.93 & 1.00 & & & \\
\hline \multirow{2}{*}{ Item 12} & Upper Group & 14 & 4.00 & 0.68 & \multirow{2}{*}{26} & \multirow{2}{*}{4.163} & \multirow{2}{*}{0.000} \\
\hline & Lower Group & 14 & 2.57 & 1.09 & & & \\
\hline \multirow{2}{*}{ Item 13} & Upper Group & 14 & 4.07 & 0.92 & \multirow{2}{*}{26} & \multirow{2}{*}{5.712} & \multirow{2}{*}{0.000} \\
\hline & Lower Group & 14 & 2.29 & 0.73 & & & \\
\hline \multirow{2}{*}{ Item 14} & Upper Group & 14 & 4.07 & 0.62 & \multirow{2}{*}{26} & \multirow{2}{*}{5.230} & \multirow{2}{*}{0.000} \\
\hline & Lower Group & 14 & 2.50 & 0.94 & & & \\
\hline \multirow{2}{*}{ Item 15} & Upper Group & 14 & 4.43 & 0.65 & \multirow{2}{*}{26} & \multirow{2}{*}{3.107} & \multirow{2}{*}{0.005} \\
\hline & Lower Group & 14 & 3.43 & 1.02 & & & \\
\hline \multirow{2}{*}{ Item 16} & Upper Group & 14 & 3.71 & 0.83 & \multirow{2}{*}{26} & \multirow{2}{*}{6.000} & \multirow{2}{*}{0.000} \\
\hline & Lower Group & 14 & 2.00 & 0.68 & & & \\
\hline \multirow{2}{*}{ Item 17} & Upper Group & 14 & 3.71 & 0.83 & \multirow{2}{*}{26} & \multirow{2}{*}{6.000} & \multirow{2}{*}{0.000} \\
\hline & Lower Group & 14 & 2.00 & 0.68 & & & \\
\hline \multirow{2}{*}{ Item 18} & Upper Group & 14 & 4.71 & 0.47 & \multirow{2}{*}{26} & \multirow{2}{*}{4.639} & \multirow{2}{*}{0.000} \\
\hline & Lower Group & 14 & 3.00 & 1.30 & & & \\
\hline \multirow{2}{*}{ Item 19} & Upper Group & 14 & 4.57 & 0.51 & \multirow{2}{*}{26} & \multirow{2}{*}{4.281} & 0000 \\
\hline & Lower Group & 14 & 3.36 & 0.93 & & & 0.000 \\
\hline $\mathrm{Jam}$ & Upper Group & 14 & 4.50 & 0.52 & 26 & 2512 & רטק00 \\
\hline nem 20 & Lower Group & 14 & 3.43 & 1.02 & 20 & 3.513 & 0.002 \\
\hline
\end{tabular}

To have a highly related group of items, each item must be highly correlated with the remaining items. For each item, this property can be analysed by calculating the item-total correlation (DeVellis, 2017). Correlation is used in the reliability studies of measurement tools. Within the scope of the reliability studies of the scale, after the Cronbach's alpha internal consistency coefficient, the corrected item-total correlation of the scale was calculated and the item total correlation explains the relationship between the points obtained from the items in the measurement tool and the total score. The high level of itemtotal correlation indicates that the items in the measurement tool exemplify similar behaviors and the internal consistency of the scale is high (Büyüköztürk, 2017). In the item analysis process of the scale, it is considered appropriate to exclude items with item-total correlations of 0.30 or less from the scale (Geuens and Pelsmacker, 2002). Results regarding the item analysis of the scale are shown in Table 2.

Table no. 2. Item Analysis Results of the Scale

\begin{tabular}{|c|c|c|}
\hline Item & Item Total Correlation* & $\begin{array}{c}\mathbf{t} \\
\text { (Upper\% 27-Lower \% 27) }^{* *}\end{array}$ \\
\hline Item 1 & 0.696 & $6.500^{* * *}$ \\
\hline Item 2 & 0.616 & $9.774 * * *$ \\
\hline Item 3 & 0.620 & $4.053 * * *$ \\
\hline Item 4 & 0.450 & $3.606 * * *$ \\
\hline Item 5 & 0.444 & $3.994 * * *$ \\
\hline
\end{tabular}




\begin{tabular}{|c|c|c|}
\hline Item & Item Total Correlation* & $\begin{array}{c}\mathbf{t} \\
\text { (Upper\% 27-Lower \% 27)** }\end{array}$ \\
\hline Item 6 & 0.325 & $3.045^{* * *}$ \\
\hline Item 7 & 0.079 & 1.427 \\
\hline Item 8 & 0.134 & 2.550 \\
\hline Item 9 & 0.647 & $6.379^{* * *}$ \\
\hline Item 10 & 0.479 & $3.823^{* * *}$ \\
\hline Item 11 & 0.531 & $4.172^{* * *}$ \\
\hline Item 12 & 0.585 & $4.163^{* * *}$ \\
\hline Item 13 & 0.588 & $5.712^{* * *}$ \\
\hline Item 14 & 0.571 & $5.230^{* * *}$ \\
\hline Item 15 & 0.536 & $3.107^{* * *}$ \\
\hline Item 16 & 0.641 & $6.000^{* * *}$ \\
\hline Item 17 & 0.652 & $6.000^{* * *}$ \\
\hline Item 18 & 0.710 & $4.639^{* * *}$ \\
\hline Item 19 & 0.647 & $4.281^{* * *}$ \\
\hline Item 20 & 0.607 & $3.513^{* * *}$ \\
\hline
\end{tabular}

Note: Significant values for $* \mathrm{n}=51, * * \mathrm{n}_{1}=\mathrm{n}_{2}=14, * * * \mathrm{p}<0.05$.

As can be seen in Table 1 and Table 2, as a result of the analyses performed, the $7^{\text {th }}$ and $8^{\text {th }}$ items with $p>0.05$ and correlation coefficients of $r \leq 0.30$ for the item averages almost do not contribute to the scale. For this reason, they were excluded from the scale.

\section{Findings and Discussion}

The draft scale developed after the pre-application was applied to a total of 205 consumers in November and December and the statistical calculations of the obtained data were made. Information on the demographic characteristics of the people who participated in the study is given in Table 3 .

Table no. 3. Demographic Characteristics of the Participants

\begin{tabular}{|c|c|c|c|}
\hline \multirow{4}{*}{ Gender } & & Frequency (n) & Percent (\%) \\
\cline { 2 - 4 } & Female & 100 & 48.8 \\
\hline \multirow{4}{*}{ Age } & Male & 105 & 51.2 \\
\cline { 2 - 4 } & $18-28$ & 35 & 17.1 \\
\cline { 2 - 4 } & $29-39$ & 85 & 41.5 \\
\cline { 2 - 4 } & $40-50$ & 63 & 30.7 \\
\cline { 2 - 4 } & $51-61$ & 17 & 8.3 \\
\hline \multirow{3}{*}{$\begin{array}{c}\text { Educational } \\
\text { Status }\end{array}$} & Primary School & 5 & 2.4 \\
\cline { 2 - 4 } & High School & 2 & 1 \\
\cline { 2 - 4 } & University & 107 & 52.2 \\
\cline { 2 - 4 } & Graduate & 73 & 35.6 \\
\hline
\end{tabular}




\begin{tabular}{|c|c|c|c|}
\hline & & Frequency $(\mathbf{n})$ & Percent (\%) \\
\hline \multirow{9}{*}{ Profession } & Unemployed & 7 & 3.4 \\
\hline & Freelancer & 8 & 3.9 \\
\hline & Government Official & 98 & 47.8 \\
\hline & Worker & 6 & 2.9 \\
\hline & Private sector & 44 & 21.5 \\
\hline & Housewife & 3 & 1.5 \\
\hline & Retired & 9 & 4.4 \\
\hline & Student & 21 & 10.2 \\
\hline & Others & 9 & 4.4 \\
\hline \multirow{7}{*}{$\begin{array}{l}\text { Monthly } \\
\text { Income }\end{array}$} & $1000 \mathrm{TL}$ and below & 24 & 11.7 \\
\hline & $1001-2000$ & 13 & 6.3 \\
\hline & $2001-3000$ & 21 & 10.2 \\
\hline & $3001-4000$ & 29 & 14.1 \\
\hline & $4001-5000$ & 43 & 21 \\
\hline & 5001TL and above & 75 & 36.6 \\
\hline & TOTAL & 205 & 100 \\
\hline
\end{tabular}

When the participants are examined by gender, it is seen that the number of female and male participants is remarkably close to each other. Nearly half of the participants are 50 years old or under. Also, it is seen that more than half of the participants are university graduates. When the professions of the participants are examined, it is understood that civil servants and students are predominant. These two groups constitute more than $50 \%$ of the research. When evaluated in terms of income level, it is seen that most of the participants have an income of $5001 \mathrm{TL}$ or more.

In the next step, the reliability of the scale was calculated. Reliability is the ability of a measurement to produce the same results under the same conditions (Field and Hole, 2019). After the main application, item analysis was applied again for the 18 -item scale. The Cronbach Alpha Reliability Coefficient of the scale consisting of 18 items was determined as $(\alpha=0.917)$. At the end of the main application, both item analysis based on the difference between lower and upper group averages and item analysis based on correlation were performed. When the results are examined, the $t$ values of the scale developed in the study are significant, and item-total correlations for all items vary between 0.457 and 0.726 . Hence, it can be said that all items in the scale are good, have high reliability, and are aimed at measuring similar behavior.

In determining the construct validity of AITUTRPS, first Exploratory Factor Analysis (EFA) and then Confirmatory Factor Analysis (CFA) were applied. Before the exploratory and confirmatory factor analyses were made, the statistical assumptions required for these analyses were checked, and the analyses were carried out after the relevant assumptions were met.

Exploratory factor analysis is often used at the beginning of research to gather more information about the interrelationships between a set of variables. Confirmatory factor analysis, on the other hand, is a more complex and advanced technique used in the later stages of the research to test specific theories and hypotheses about the underlying structure of a number of variables (Pallant, 2016). 
The first of the values examined in the exploratory factor analysis is the Kaiser-MeyerOlkin Sampling Adequacy Scale (KMO) and Bartlett's Sphericity test results, which are used to determine whether the sample is suitable for factor analysis. If the value of the Kaiser-Meyer-Olkin test is below 0.50, factor analysis is not continued. If the value for the sample size is between 0.50-0.60, it is interpreted as Bad, if between 0.60-0.70, Poor, if between 0.70-0.80, Medium, if between 0.80-0.90, Good and if it is above 0.90, Excellent. (Leech, Barrett and Morgan, 2005).

The KMO value for AITUTRPS was calculated as 0.840 . This value indicates that the sampling efficiency of the research is at a good level for factor analysis. Also, when the Barlett sphericity test results were examined, it was seen that the chi-square value was significant $\left(\chi^{2}(91)=2056.359 ; \mathrm{p}<0.01\right)$. In this direction, it was accepted that the data came from multivariate normal distribution. In line with these findings, exploratory factor analysis was applied to the data.

In order to determine the factor pattern of the scale consisting of 18 variables, Principal Component Analysis was used as the factoring method, and Varimax rotation, one of the most frequently used rotations which gives the most sensitive distinction between factors, was used in order to interpret the factors more meaningfully as a rotation method (Ho, 2006). As a result of the analysis, it was found that AITUTRPS had four factors and the ratio of explaining the total variance of these four factors was $77.905 \%$. Generally, it is recommended that the total variance explained by all factors in exploratory factor analysis should be at least $30 \%$ in unidimensional scales and at least $50 \%$ in multidimensional scales (Streiner, 1994). Accordingly, the variance value explained by AITUTRPS is quite high. When each factor is examined, the first factor explains $22,055 \%$ of the total variance, the second factor explains $19,836 \%$ of the total variance, the third factor explains $18,129 \%$ of the total variance, and the fourth factor explains $17,885 \%$ of the total variance. In Table 4 , four factors and factor load of each variable belonging to these factors are shown.

Table no. 4. AITUTRPS Exploratory Factor Analysis Results

\begin{tabular}{|l|c|c|c|c|}
\hline \multirow{2}{*}{ Variables } & \multicolumn{3}{c|}{ Components } \\
\cline { 2 - 5 } Harm_Employees & 1 & 2 & 3 & 4 \\
\hline Harm_Customers & 0.862 & & & \\
\hline Harm_People & 0.843 & & & \\
\hline Watching_Humans & 0.837 & & & \\
\hline Protect_Data & 0.770 & & & \\
\hline Hack_Accounts & & 0.803 & & \\
\hline Capture_Personal_Information & & 0.794 & & \\
\hline Use_Maliciously & & 0.752 & & \\
\hline Affect_Decision & & 0.739 & & \\
\hline Direct_To_Purchase & & & 0.892 & \\
\hline Click_On_Ads & & & 0.837 & \\
\hline Service_Sector & & & & 0.752 \\
\hline Manufacturing_Sector & & & & 0.851 \\
\hline Retail_Sector & & & & 0.835 \\
\hline
\end{tabular}


In the exploratory factor analysis, a factor load should be at least 0.30 . Also, the difference between the factor loads given by a variable to more than one factor must be at least 0.1 (Stevens, 2002). Factor load is the correlation of an item or an observed variable with the relevant factor. Or it is the rate at which variables contain the essence or hidden variable of each factor. The square of the factor loading of an item within the factor shows how much of the variance in the relevant factor explains. A low factor load value of an item indicates that that item is insufficient to explain the relevant factor (Gürbüz and Şahin, 2018).

According to Tabachnick and Fidell (2013), the factor load of an item on a factor should be minimum 0.32. As a result of this analysis, the factor loads of the $3^{\text {rd }}, 9^{\text {th }}, 10$ th and $13^{\text {th }}$ items were removed from the scale since the factor loads were spread over more than one dimension and these items were located in a dimension different from the theoretically determined ones. With the exclusion of these items from the scale, the general reliability level of the scale consisting of 14 items, was calculated as 0.917 , which shows that the reliability of the scale is quite high. Detailed information on the factors resulting from the analysis is given below.

\section{Factor 1. Security Issue}

Four items were given under the first factor, and these items, load values and other statistical values are shown in Table 5. This factor was named Security Issues.

Table no. 5. Information on the Security Issues Factor

\begin{tabular}{|l|r|r|}
\hline \multicolumn{3}{|c|}{ FACTOR 1. SECURITY ISSUES } \\
\hline Item & Factor Load & Common Variance \\
\hline Harm_Employees & 0.862 & 0.861 \\
\hline Harm_Customers & 0.756 & 0.843 \\
\hline Harm_People & 0.739 & 0.779 \\
\hline Watching_Humans & 0.685 & 0.643 \\
\hline \multicolumn{2}{|c|}{ Cronbach's Alpha: $\mathbf{0 . 8 9 7}$, Eigenvalues: 6.287 , Variance Explained: 22.055 } \\
\hline
\end{tabular}

It was determined that the factor loadings of the Security Issues were between 0.685 and 0.862 . Cronbach's Alpha value of the factor was 0.897 . This value shows that the factor is highly reliable. The security issues factor explains $22,055 \%$ of the total variance.

In Factor Analysis, an item can correlate with more than one factor. Common variances are the sum of squares of correlation with the factors with which an item is associated. The extraction value corresponding to the common variance value of an item shows the total variance explained by that item (Gürbüz and Şahin, 2018) When interpreting common variance values, it is stated that 0.50 is generally required as a criterion (Thompson, 2004). However, it is not always possible to reach high common variance values in the social sciences. Therefore, Costello and Osborne (2005) stated that it would be more appropriate to take a value of 0.40 for the common variance as a criterion. Tabachnick and Fidell (2013) stated that items with a common variance of less than 0.20 indicate the heterogeneity between items. It is possible to say that the common variance of all items is good since the common variance values for the Security Issues factor is between 0.643 and 0.861 . 
Factor 2. Violation of Personal Privacy

Four items were given under the second factor, and these items, load values and other statistical values are shown in Table 6. This factor was named Personal Privacy Violation.

Table no. 6. Information on Personal Privacy Violation Factor

\begin{tabular}{|l|r|r|}
\hline \multicolumn{3}{|c|}{ FACTOR 2. VIOLATION OF PERSONAL PRIVACY } \\
\hline \multicolumn{1}{|c|}{ Item } & Factor Load & $\begin{array}{c}\text { Common } \\
\text { Variance }\end{array}$ \\
\hline Protect_Data & 0.803 & 0.705 \\
\hline Hack_Accounts & 0.794 & 0.765 \\
\hline Capture_Personal_Information & 0.752 & 0.773 \\
\hline Use_Maliciously & 0.739 & 0.740 \\
\hline \multicolumn{2}{|c|}{ Cronbach's Alpha: 0.873, Eigenvalues: 1.882 , Variance Explained: 19.836} \\
\hline
\end{tabular}

It was determined that the factor loadings of the privacy violation are between 0.739 and 0.803 . Cronbach's Alpha value of the factor is 0.873 . This value shows that the factor is highly reliable. The Personal Privacy Violation factor explains $19.836 \%$ of the total variance. Since the common variance values for the Personal Privacy Violation factor are between 0.705 and 0.773 , it can be said that the common variance of all items is good.

\section{Factor 3. Ethical Issues}

Three items were given under the third factor, and these items, load values and other statistical values are shown in Table 7. This factor was named Ethical Issues.

Table no. 7. Information on the Ethical Issues Factor

\begin{tabular}{|l|r|r|}
\hline \multicolumn{3}{|c|}{ FACTOR 3: ETHICAL ISSUES } \\
\hline Item & Factor Load & Common Variance \\
\hline Affect_Decision & 0.892 & 0.871 \\
\hline Direct_To_Purchase & 0.837 & 0.792 \\
\hline Click_On_Ads & 0.752 & 0.695 \\
\hline Cronbach's Alpha: 0.866, Eigenvalues: 1.671 , Variance Explained: 18.129 \\
\hline
\end{tabular}

Factor loads of Ethical Issues were determined to be between 0.752 and 0.892 . Cronbach's Alpha value of the factor is 0.866 . This value shows that the factor is highly reliable. The Personal Privacy Violation factor explains $18.129 \%$ of the total variance. Since the common variance values for the Ethical Issues factor are between 0.695 and 0.866 , it can be said that the common variance of all items is good.

\section{Factor 4. The Employment Issue}

Three items were given under the fourth factor, and these items, load values and other statistical values are shown in Table 8. This factor was named Employment Issue. 
Table no. 8. Information on the Employment Issue Factor

\begin{tabular}{|l|r|r|}
\hline \multicolumn{3}{|c|}{ FACTOR 4: THE EMPLOYMENT ISSUE } \\
\hline Item & Factor Load & Common Variance \\
\hline Service_Sector & 0.892 & 0.862 \\
\hline Manufacturing_Sector & 0.851 & 0.801 \\
\hline Retail_Sector & 0.835 & 0.777 \\
\hline \multicolumn{2}{|c|}{ Cronbach's Alpha: 0.866, Eigenvalues: 1.068, Variance Explained: 17.885} \\
\hline
\end{tabular}

Factor loadings of the Employment Issue were determined to be between 0.835 and 0.892 . Cronbach's Alpha value of the factor is 0.866 . This value shows that the factor is highly reliable. The Employment Issues factor explains $17.885 \%$ of the total variance. Since the common variance values for the employment issues factor are between 0.777 and 0.862 , it can be said that the common variance of all items is good. In the process of developing a scale, explanatory factor analysis is used as an explanatory first step, while confirmatory factor analysis can be used as a second step to check the operability of a structure defined by exploratory factor analysis (Harrington, 2009). In this direction, confirmatory factor analysis was performed on the data.

Many fit indices are used to determine the adequacy of the model tested in the confirmatory factor analysis. Since the fit indices have strengths and weaknesses relative to each other in evaluating the fit between the theoretical model and the real data, different fit indices should be used to comment on the fit of the model. Fit indices were used in the study to test the accuracy and fit of the model determined by factor analysis.

As a result of the exploratory factor analysis, the compatibility of the remaining 14 items of AITUTRPS to the model was tested through confirmatory factor analysis. The values of the scale items were examined in terms of fit indices. The relevant dimensions of AITUTRPS, which was determined to consist of four factors by applying exploratory factor analysis, were tested with first-level multifactorial confirmatory factor analysis. For this purpose, the model of primary level multifactorial confirmatory factor analysis was created. The latent factors in the scale and the mutual effects between these factors were evaluated within the framework of the model created. First Level Multi-Factor Confirmatory Factor Analysis Diagram for AITUTRPS is shown in Figure 1.

According to CFA, it was determined that the structural equation model result of the scale was significant at the level of $\mathrm{p}=0.000$, and the 14 items and four sub-factors forming the scale were related to the scale structure. Also, improvements were made in the model. While making improvements, variables that decrease the fit value were determined, and new covariance's were created for those with high covariance among residual values. In the renewed fit index calculations, acceptable values for fit indices are shown in Table 9. 


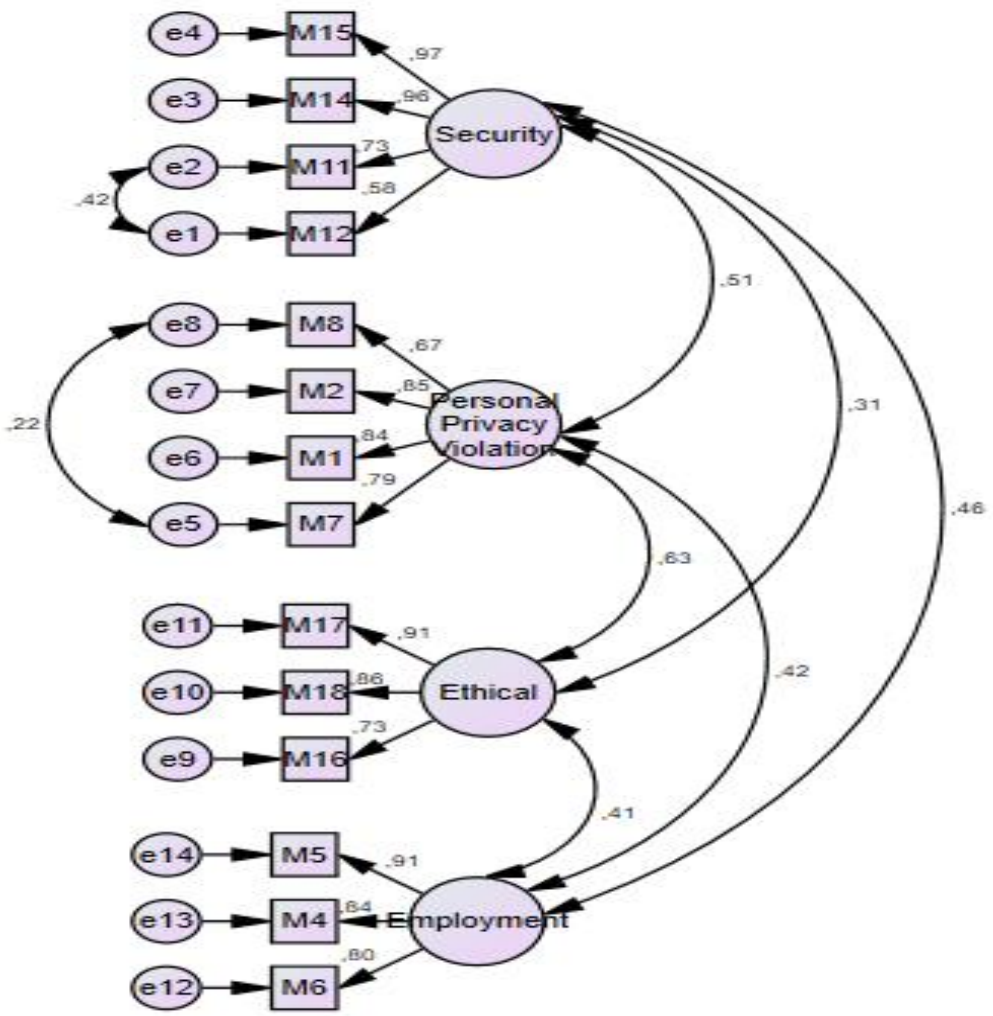

Figure no. 1. First Level Multi-Factor Confirmatory Factor Analysis Diagram for AITUTRPS

Table no. 9. AITUTRPS First Level Multifactor Confirmatory Factor Analysis Fit Indices

\begin{tabular}{|l|c|c|c|c|c|}
\hline $\begin{array}{c}\text { Fit } \\
\text { Criteria }\end{array}$ & Good Fit* & $\begin{array}{c}\text { Acceptable } \\
\text { Fit* }\end{array}$ & $\begin{array}{c}\text { Calculated } \\
\text { Value Before } \\
\text { Modification }\end{array}$ & $\begin{array}{c}\text { Calculated } \\
\text { Value After } \\
\text { Modification }\end{array}$ & Fit Status \\
\hline CMIN/Df & $0 \leq \chi^{2} / \mathrm{df} \leq 3$ & $3 \leq \chi^{2} / \mathrm{df} \leq 5$ & 2.659 & 2.083 & Good Fit \\
\hline GFI & $\geq 0.95$ & $\geq 0.90$ & 0.892 & 0.916 & Acceptable Fit \\
\hline CFI & $\geq 0.95$ & $\geq 0.90$ & 0.942 & 0.963 & Good Fit \\
\hline RMSEA & $\leq 0.05$ & $\leq 0.08$ & 0.090 & 0.073 & Acceptable Fit \\
\hline
\end{tabular}

When the values in Table 9 are analysed, it is seen that the CMIN/df after the modification is 2.083, the GFI value is 0.916 , the CFI value is 0.963 , and the RMSEA value is 0.073 . Since these values are within acceptable limits, the four-factor structure of AITUTRPS was confirmed. In addition, factor loads for each factor are given in Table 10. 
Table no. 10. Factor Loadings as a Result of Confirmatory Factor Analysis for AITUTRPS

\begin{tabular}{|c|c|}
\hline Factors and Items & $\begin{array}{l}\text { Factor } \\
\text { Loadings }\end{array}$ \\
\hline \multicolumn{2}{|l|}{ Security Issues } \\
\hline $\begin{array}{l}\text { I am afraid that an AI robot used as a cashier, aisle or warehouse attendant } \\
\text { in a store could spiral out of control and harm other employees. }\end{array}$ & 0.96 \\
\hline $\begin{array}{l}\text { I am afraid that an AI robot used as a cashier, aisle or warehouse attendant } \\
\text { in a store could spiral out of control and harm customers. }\end{array}$ & 0.97 \\
\hline $\begin{array}{l}\text { I am afraid that a product controlled by artificial intelligence technology } \\
\text { (e.g. a driverless vehicle) could spiral out of control and harm people. }\end{array}$ & 0.73 \\
\hline $\begin{array}{l}\text { I think that an AI product (e.g. robot, drone, smart car) can lead to } \\
\text { undesirable results when it learns by watching human behaviour patterns. }\end{array}$ & 0.58 \\
\hline \multicolumn{2}{|l|}{ Violation of Personal Privacy } \\
\hline $\begin{array}{l}\text { I think that enough measures have not been taken to protect my data } \\
\text { collected by using artificial intelligence technology. }\end{array}$ & 0.67 \\
\hline $\begin{array}{l}\text { When I shop from a site that uses artificial intelligence technology, I am } \\
\text { concerned that fraudsters may hack my accounts. }\end{array}$ & 0.85 \\
\hline $\begin{array}{l}\text { I think that my personal information can be captured because of the artificial } \\
\text { intelligence technologies used while shopping on the Internet. }\end{array}$ & 0.84 \\
\hline $\begin{array}{l}\text { I am concerned that the information obtained by artificial intelligence } \\
\text { technology can be used maliciously (acting on behalf of the person against } \\
\text { his will, etc.). }\end{array}$ & 0.79 \\
\hline \multicolumn{2}{|l|}{$\begin{array}{ll}\text { Ethical Issues } \\
\end{array}$} \\
\hline $\begin{array}{l}\text { I think that artificial intelligence technology affects the decision-making } \\
\text { process of an individual by learning and monitoring the preferences on the } \\
\text { Internet. }\end{array}$ & 0.91 \\
\hline $\begin{array}{l}\text { With artificial intelligence technology, I think an individual is monitored on } \\
\text { the Internet and directed to purchase through his preferences. }\end{array}$ & 0.86 \\
\hline $\begin{array}{l}\text { I think companies develop computer-based applications on the Internet for } \\
\text { us to click on ads. }\end{array}$ & 0.73 \\
\hline \multicolumn{2}{|l|}{ The Employment Issue } \\
\hline $\begin{array}{l}\text { I think that artificial intelligence technology may unemploy people working } \\
\text { in the service sector (robot waiter, etc.) in the future. }\end{array}$ & 0.91 \\
\hline $\begin{array}{l}\text { I think that artificial intelligence technology may unemploy people working } \\
\text { in the manufacturing sector (robots, etc.) in the future. }\end{array}$ & 0.84 \\
\hline $\begin{array}{l}\text { I think that artificial intelligence technology may unemploy people working } \\
\text { in the retail sector (store without a cashier, etc.) in the future. }\end{array}$ & 0.80 \\
\hline
\end{tabular}

\section{Conclusions}

Artificial intelligence technologies, which are increasingly prominent today, have positive impacts on many industries. It is a fact that these technologies are gradually getting more and more attention from companies and investors. Artificial intelligence technology provides advantages in various issues such as analysing the demands and needs of customers well, offering the right product for them, making price comparison, especially in 
the field of wholesale and retail trade, and it enables businesses to develop effective and efficient sale strategies in the digital environment. Developing artificial intelligence technologies, unfortunately, cause differences of opinion between scientists and business people. While some defend the positive aspects of this technology, many scientists and businessmen claim that it may cause various problems and even be dangerous if not used carefully.

When the literature on the use of artificial intelligence in wholesale and retail trade is examined, it is seen that there are some issues related to the artificial intelligence technologies used in selling, such as security, privacy, employment, and ethics. When these problems are evaluated, it is predicted that artificial intelligence technology can cause security problems when it is out of control, it can violate personal privacy as it reaches billions of personal information, and it may cause many job losses and increase unemployment, especially in the retail and service sector. It is also understood that these technologies may ignore some ethical values.

While many applications with artificial intelligence technologies, such as driverless vehicles, facial recognition technologies, and personal assistants that offer suggestions by analysing human face, continue to develop and bring many advantages, the issues that this technology may create must be taken seriously. These technologies, which may become difficult to control as they develop, must be planned and implemented carefully and cautiously. In the study, considering the information obtained from the literature, Artificial Intelligence Technologies Used in Trade Risk Perception Scale (AITUTRPS) was developed. The reason for the development of this scale is that there is no specific scale in the literature to measure the risk perceptions of consumers towards artificial intelligence technologies used in wholesale and retail trade. Thus, it is aimed to fill this gap in the literature. Expert opinions were used in determining content validity during the scale creation phase. The scale was piloted in the first stage, and items that reduced validity and reliability were removed from the scale. The draft scale after this process was applied to 205 people, and the results were subjected to explanatory and confirmatory factor analysis. In this part, it can be said that the use of both explanatory factor analysis and confirmatory factor analysis makes the study more reliable. As a result of the analysis, four dimensions, namely security issue, violation of personal privacy, unemployment issues and ethical issues, occurred. The rate of explaining the total variance of these four factors was found to be $77.905 \%$.

Among the security issues, there are problems such that an artificial intelligence robot used as a cashier, aisle or warehouse clerk in a store can get out of control and harm other employees or customers. To avoid these problems, it is beneficial to make continuous controls of this robot, and it should be monitored by an expert. The possibility of a product such as a driverless vehicle controlled by artificial intelligence technology to get out of control and harm people is another security-related issue. This issue should be prevented at the production stage, and all necessary measures should be taken to prevent such a situation. As for the violation of personal privacy, there are concerns that personal data collected by artificial intelligence technology may be intercepted, misused and that this data is not adequately protected. It is useful to prevent this problem with necessary software and legal regulations and sanctions. With artificial intelligence technology, ethical issues such as monitoring the preferences of the person on the Internet and learning their preferences and affecting their purchasing decision process or directing them to purchase are also encountered. Firms should not include such practices that take place against the will of the 
consumers, because this may damage the image of the firm or negatively affect the attitudes of consumers towards the firm or the brand. The fact that artificial intelligence technology may leave people working in the production, service, and retail sectors unemployed in the future creates employment issues. Regarding this issue, states and authorities must take precautions and limit the number of robots working with artificial intelligence technology.

This study is significant in terms of addressing the ignored AI risks while people continuously highlight the positive aspects of the AI in today's world. In this direction, the developed scale is likely to become a basis for researchers who want to work on this subject in the future. By using this scale in the future, the subject can be addressed from various angles and different studies can be conducted. Besides, by using this scale, the differences in perception of risks related to artificial intelligence technologies used in wholesale and retail trade in terms of demographic characteristics such as gender, age, income and profession, or how these risks are perceived by people from different segments such as trade professionals, marketing professionals, entrepreneurs, engineers, computer programmers can be investigated. By using this research tool, multidisciplinary studies and projects can be developed, which can be useful to the academic and business environment. In addition, this scale can be useful for companies that want to develop different marketing strategies using artificial intelligence technologies. Risks that may arise and how these risks are perceived by consumers are important for the implementation of correct strategies.

\section{References}

Altan, S., 2019. Two pricing AIs collaborated and overcharged people, [online] Available at: <https://pazarlamasyon.com/iki-fiyatlandirma-yapay-zekasi-birlik-olup-insanlarikazikladi/.> [Accessed 25 January 2020].

Antonio, V., 2017. Nike Goes AI with Nikeid.com, [online] Available at: <http://www.sellingergroup.com/ai-in-sales/nike-goes-ai-with-nikeidcom.> [Accessed 10 December 2019].

Ayvaz, T., 2014. Marshall Augmented Reality Application: Visualizer, [online] Available at <http://www.dijitalajanslar.com/marshall-artirilmis-gerceklik-uygulamasi-visualizer/> [Accessed 26 March 2020].

BBC, 2015. Microsoft's Bill Gates insists AI is a threat, [online] Available at: <https://www.bbc.com/news/31047780> [Accessed 18 November 2019].

$\mathrm{BBC}, 2018$. What are the dangers that artificial intelligence can bring in 10 years? [online] Available at: <https://www.bbc.com/turkce/haberler-43144059> [Accessed 15 December 2019].

Bostrom, N., 2014. Superintelligence: Paths, Dangers, Strategies. Oxford: Oxford University Press.

Bowling, M., Burch, N., Johanson, M. and Tammelin, O., 2015. Heads-up Limit Hold'em Poker is Solved. Science, 347(6218), pp.145-149. https://doi.org/10.1126/ science. 1259433.

Brockman, J., 2015, What to Think About Machines That Think: Today's Leading Thinkers on the Age of Machine Intelligence. New York: Harper Perennial.

Bryman, A. and Cramer, D., 2001. Quantative Data Analysis with SPSS Release 10 For Windows. London: Routledge. 
Büyüköztürk, Ş., 2017. Data Analysis Handbook For Social Sciences (23rd Edition). Ankara: Pegem Academic Publishing.

CNNTURK., 2018. Amazon's robot damaged 24 employees, [online] Available at: <https://www.cnnturk.com/dunya/amazonun-robotu-24-calisani-hastanelik-etti.> [Accessed 20 December 2019].

Cohen, L., Manion L. and Morrison, K., 2007. Research Methods in Education. New York: Routledge.

Costello, A.B. and Osborne, J.W., 2005. Best Practices in Exploratory Factor Analysis: Four Recommendations for Getting the Most from Your Analysis. Practical Assessment Research \& Evaluation, 10(7), pp.1-9.

Dedeoğlu, G., 2006. Ethical Issues in the Information Society, II. Applied Ethics Congress, 18-20 October, METU, Ankara.

DeVellis, R.F., 2017. Scale Development (Trans. Tarlk Totan). Ankara: Nobel Publishing.

Dirican, C., 2015. The Effects of Technological Development and Artificial Intelligence Studies on Marketing. Journal of Management Marketing and Logistics, 2(3), pp. 178-190. https://doi.org/10.17261/Pressacademia.2015312948.

Econsultancy, 2018. Dream vs. Reality: The State of Consumer-First and Omnichannel Marketing. Market Data, London: Econsultancy.com Ltd.

Euronews, 2018. Transkribus: Historical manuscripts digitalize thanks to artificial intelligence, [online] Available at: <https://tr.euronews.com/2018/11/03/yapay-zekasayesinde-el-yazisini-okuyabilen bilgisayarlar> [Accessed 17 April 2020].

Field, A. and Hole, G., 2019. How to Design and Report a Research. (Trans. Arif Ozer), Ankara: Ani Publishing.

Geuens M. and De Pelsmacker P., 2002. Validity and reliability of scores on the reduced Emotional Intensity Scale. Educational and Psychological Measurement. [e-jourmal] 62 (2), pp: 299 -315. https://doi.org/10.1177/0013164402062002007.

Gürbüz, S. and Şahin, F., 2018. Research Management in Social Sciences. PhilosophyMethod-Analysis. Ankara: Seçkin Publishing.

Harrington, D., 2009. Assessing Confirmatory Factor Analysis Model Fit and Model Revision. Confirmatory Factor Analysis (1 st Edition). New York: Oxford University.

Henkoğlu, T., 2019. Risk Assessment for the Use of Artificial Intelligence Systems in Information Storage Processes. Archive World, 6(2), pp.134-147.

Ho, R., 2006. Handbook of Univariate and Multivariate Data Analysis and Interpretation with SPSS. Florida: Chapman \& Hall/CRC.

Jones, R.C., 2014. Hawking: Artificial intelligence could bring about the end of humanity, [online] Available at: <https://www.bbc.com/turkce/haberler/2014/12/141202_ hawking_yapay_zeka> [Accessed 19 November 2019].

Kietmann, J., Paschien J. and Trieen E., 2018. Artificial Intelligence in Advertising How Marketers Can Leverage Artificial Intelligence Along the Consumer Journey. Advertising Research Journey, 58(3), pp.263-267. https://doi.org/10.2501/jar-2018-035.

Kline, R.B., 2005. Principles and Practice of Structural Equation Modeling (2nd Edition). New York: The Guilford Press. 
Knight, W., 2017. The Dark Secret at the Heart of AI, [online] Available at <https://www.technologyreview.com/s/604087/the-dark-secret-at-the-heart-of-ai/> [Accessed 10 October 2019].

Köse, U., 2018a. Artificial Intelligence: Paradoxes in Future Science. Popular Science, 25(261), pp.12-21.

Köse, U., 2018b. Artificial intelligence and the future: Should we worry? Science and Utopia, 284(24), pp.39-44.

Kulabaş, A., 2017. Smart Hologram Technology, [online] Available at: <https://medium.com/@AyseKulabas/ak1ll1-hologram-teknolojisi59faa8915f27> [Accessed 12 September 2019].

Leech, N.L., Barrett, K.C. and Morgan, G.A., 2005. SPSS for Intermediate Statistics: Use and Interpretation (2nd Ed). Mahwah, NJ: Lawrence Erlbaum Associates.

Levi Strauss \& Co., 2017. Levi's launches new 'virtual stylist' online feature, [online] Available at: <https://www.levistrauss.com/unzipped-blog/2017/08/31/levis-launchesnew-virtual-stylist-online-feature/>[Accessed 18 September 2019].

Morris, D.Z., 2017. Nearly Half of All Retail Jobs Could be Lost to Automation within 10 Years, [online] Available at: <http://fortune.com/2017/05/21/automation-retail-joblosses/> [Accessed 20 April 2020].

O'Shea, D., 2017. West Elm taps Pinterest images for product recommendations, [online] Available at: <https://www.retaildive.com/news/west-elm-taps-pinterest-images-forproduct-recommendations/446563/> [Accessed 20 December 2019].

Pallant, J., 2016. SPSS User Guide - Step-by-Step Data Analysis with SPSS. (Trans. S. Balcı \& B. Ahi). Ankara: Ani Publishing.

Parry, K., Cohen, M. and Bhattacharya, S., 2016. Rise of The Machines: A Critical Consideration of Automated Leadership Decision Making in Organizations. Group and Organization Management, 41(5), pp.571-594. https://doi.org/10.1177/ 1059601116643442.

PC World, 2011. IBM Watson Vanquishes Human Jeopardy Foes, [online] Available at: <https://www.pcworld.com/article/219893/ibm_watson_vanquishes_human_jeopardy_ foes.html> [Accessed 19 December 2019].

Pittman, R.J., 2016. Say 'Hello' to eBay ShopBot Beta, [online] Available at: <https://www.ebayinc.com/stories/news/say-hello-to-ebay-shopbot-beta/> [Accessed 18 October 2019].

Russell, S., 2015. Will they make us better people?, [online] Available at: <http://edge.org/response-detail/26157> [Accessed 03 November 2019].

Seçer, I., 2015. Psychological test development and adaptation process: SPSS and LISREL Aplications. Ankara: Anı Publishing.

Şentürk, B., 2018. Artificial intelligence (AI) in marketing - How UPS did It?, [online] Available at: <https://pazarlamaturkiye.com/makale/pazarlamada-yapay-zeka-ai-upsbunu-nasil-yapti/> [Accessed 13 November 2019].

Shavel, M., Vanderzeil, S. and Currier, E., 2017. Retail Automation: Stranded Workers? Opportunities and risks for labor and automation, Global Thematic Research. IRRC Institute: Cornerstone Capital Group. 
Silver, N., 2012, The Signal and the Noise: Why So Many Predictions Fail - But Some Don't. New York: The Penguin Press.

Statista, 2020. Revenues from the artificial intelligence (AI) software market worldwide from 2018 to 2025 (In Billion U.S. Dollars), [online] Available at: <https://www.statista.com/statistics/607716/worldwide-artificial-intelligence-marketrevenues/> [Accessed 11 June 2020].

Sterne, J., 2017. Artificial Intelligence for Marketing: Practical Applications. New Jersey: John Wiley \& Sons, Inc.

Stevens, J.P., 2002. Applied Multivariate Statistics for The Social Sciences (Fourth Edition). New Jersey: Lawrance Erlbaum Association.

Streiner, D.L., 1994. Figuring Out Factors: The Use and Misuse of Factor Analysis. Canadian Journal of Psychiatry, 39(3), pp.135-140. https://doi.org/10.1177/ 070674379403900303.

Tabachnick, B.G. and Fidell, L.S., 2013. Using Multivariate Statistics. Boston: Pearson Education.

The Associated Press, 2017. For driverless cars, a moral dilemma: who lives and who dies?, [online] Available at: <https://www.nbcnews.com/tech/innovation/driverless-carsmoral-dilemma-who-lives-who-dies-n708276> [Accessed 12 October 2019].

The Guardian, 2015. Elon Musk donates \$10m to keep artificial intelligence good for humanity, [online] Available at: <https://www.theguardian.com/technology/2015/jan/16/ elon-musk-donates-10m-to-artificial-intelligence-research> [Accessed 12 October 2019].

Thiraviyam, T., 2018. Artificial Intelligence Marketing. International Journal of Recent Research Aspects, 4(Special Issue), pp.449-452.

Thompson, B., 2004. Exploratory and Confirmatory Factor Analysis: Understanding Concepts and Applications. Washington DC: American Psychological Association.

Tjepkema, L., 2019. What Is Artificial Intelligence Marketing \& Why Is It So Powerful, [online] Available at: <https://www.emarsys.com/en/resources/blog/artificialintelligence-marketing-solutions/ > [Accessed 12 April 2020].

Tüfekçi, Z., 2018. We create a dystopia for people to click on ads, [online] Available at: $<$ https://www.ted.com/talks/zeynep_tufekci_we_re_building_a_dystopia_just_to_make _people_click_on_ads/transcript?language=tr> [Accessed 26 March 2020].

Ulutaş Ertuğrul, T., 2019. What were the sectors pushing the limits of artificial intelligence in 2019?, [online] Available at: <https://pazarlamasyon.com/2019da-yapay-zekaninsinirlarini-zorlayan-sektorler-nelerdi/> [Accessed 20 April 2020].

Wakefield, J., 2018. What are the dangers of artificial intelligence in 10 years?, [online] Available at: <https://www.bbc.com/turkce/haberler-43144059> [Accessed 07 November 2019].

Yamak, M., 2017. The cafe of the future where robots prepare all coffees: Café X, [online] Available at: <https://www.webtekno.com/tum-kahveleri-robotlarin-hazirladigigelecegin-kafesi-cafe-x-h24913.html> [Accessed 10 December 2019].

Young, J. and Cormier, D., 2014. Can Robots Be Managers, Too? Harvard Business Review, [online] Available at: <http://blogs.hbr.org/2014/04/can-robots-bemanagerstoo/> [Accessed 12 October 2019]. 